\title{
Studying the Compatibility of Iran's New Primary School Curriculum with the Curriculum Change Principles
}

\author{
Maghsoud Amin Khandaghi ${ }^{1}$ \& Ali Baraei ${ }^{2}$ \\ 1 Associate Professor, Ferdowsi University of Mashhad, Iran \\ ${ }^{2}$ Ph.D. Candidate in Curriculum studies at Ferdowsi University of Mashhad, Iran
}

Correspondence: Maghsoud Amin Khandaghi, Ferdowsi University of Mashhad, Iran. E-mail: aminkhandaghi@ferdowsi.um.ac.ir, abaraei@yahoo.com

Received: May 27, 2016

doi:10.5539/mas.v11n7p13
Accepted: June 8, 2016

Online Published: May 14, 2017

URL: https://doi.org/10.5539/mas.v11n7p13

\begin{abstract}
Some principles are key to any change process and considering them in practice make the change process effective. The advocators for "down-up" change believe that the thoughts and ideas of individuals with practical and direct experience of the situation are more effective for making change. As main actors of curriculum, teachers have beneficial views on change plans. This survey aimed to investigate the primary school teachers' viewpoints on the compatibility between Iran's Primary School Curriculum changes and the 12 Curriculum Change Principles. Finding showed that in Iran's primary school curriculum, the principles relating to learning as an agent needed for change (principle 1), intervention for making change (principle 5), district and school-based leadership as an essential elements of long-term change success (principle 7), systematic view on change (principle 11), considering the school as the primary organizational unit for change (principle 3 ) and focus on objectives (principle 12) are highly considered. However, organizational and individual roles in making change (principle 4) and appropriate intervention role in reducing resistance to change (principle 4) are less considered by the subjects. Some differences were significant based on other background variables, too.
\end{abstract}

Keywords: Primary School Curriculum, Change Principles, teacher

\section{Introduction}

One of the reasons for making change in all fields is related to the economic and technological effects of globalization (wedell, 2009). In our ever-changing world with its continuous development in information and communication technology (ICT), modern society's expectations of educational system increases. As a result, it is expected that the educational system, especially that of curriculum adjusts itself to these ever-changing requirements. This requires "curriculum change" (Mehrmohammadi, 2012).

Curriculum change is a domain that has a close relation to curriculum implementation domain. The definition of curriculum change heavily depends on the accepted definition of curriculum. Therefore, if we defines curriculum as something including among others, education philosophy, values, objectives, organizational structures, students' experiences, learning outcomes and their evaluation, curriculum change can include all changes made in these aspects (Fathi-vajarghah, 2009).

The studies in this domain showed that some principles are key to change process and repeated in many studied patterns. These "principles of change" are of some well-known and accepted aspects of change. In the late 1960s, a research group in Texas University, Austin collaborated in identifying the principles of change in educational system. From 1970 t0 1986, they started to study the trend of change in schools and universities. Some researchers from the United States, Belgium, Holland, Australia, Canada, Taiwan, Hong-Kong and others connected to the group for more help and confirmation (Hall and Hord, 2015). They extracted 12 main principles as "Curriculum Change Principles"for change as follows:

Principle 1: Change Is Learning (Change needs some learning).

Wedell(2009) pointed out that this principle manifests itself in new needs individuals have in their personal and occupational affaires and they require this principle to better encounter change. 
Principle 2: Change is a process, not a simple event.

Wedell(2009) argue that the change process is a relatively long-term activity. Fullan (1985) conceives curriculum change as a process including the phases of initiation, use and revision. In another study, Fullan (2005) enumerated 9 main steps for making large scale change: 1) Analyzing district context issues as an exploratory step in which all stakeholders determine the requirements and conditions for making great change; 2) Creating a district steering committee for monitoring and critically evaluating the change process; 3 ) Developing an informal section for understanding the unites involved in the process and establishing a representative organization for facilitation: 4) Orienting the central office staff and key community members; 5) Creating an executive work group: 6) Providing facilitators and timetables of educational events for schools, central staff and school employees; 7) Facilitating, monitoring and changing the process of the implementation of the School Development Plan based on an appropriate documentation procedure; 8) Developing a set of useful outcomes directly related to national, state and regional objectives in mathematics, fine arts, science, social sciences, etc.; and 9) Developing a revision section for annually revising the activities planned for staff and identifying administrational units that need more consideration.

Principle 3: The school is the primary organizational unit for change.

All who involve in the process of curriculum change confirmed the importance and necessity of teachers' role in this process (Hargreaves and Evans, 1997; Aitken and Higgs, 2015; Fitz, Davies and Evans, 2006; Hall and Hord, 2015). Schools as the primary working centers for teachers and their key instructional activities are main places of starting and making change.

Principle 4: Organizations adopt change and individuals implement change.

Fullan (1985) said that there are two perspectives on the process of curriculum change: fidelity and adaptation. The latter is inflexible and open for educational process in which the phases of development and use are conceived as a continuous change made by the stakeholders. One of the concepts of this principle is adoption that makes change process close to use. Adoption tends to help a curriculum or a particular curriculum to be oriented.

Principle 5: Interventions are key to the success of the change process.

The book entitled Curriculum Change in Secondary Schools: 1957-2004 (evans, 2006) shows how an increase in central government's intervention can affect education quality.

Principle 6: Appropriate interventions reduce resistance to change.

Resistance to change is a notion some people made for remaining rigid and some people consciously try to destroy activities for making change. Any professional or individual change made in educational system causes some doubt (Wedell, 2009). The solution is to find out the reasons for resistance. Some may think that change cannot be effective. However, it is need to say them that change is a difficult, but inevitable notion. Resistance to change has several reasons, including among others individual reasons.

Principle 7: District and school-based leadership Is essential to long-term change success.

It is clear that change is not easy to manage. It has been confirmed that a well-managed change-making process can result in significant success in achieving the goals (Aitken and Higgs, 2010).

Principle 8: Facilitating change is a team effort.

Some factors cause change to be a complex event that its management needs an organizational background and group work. These factors include an increase in competition level, a demand for budgeting, globalization, change in the nature of workforce, new regulations and technologies, etc. (Aitken and Higgs, 2010: 24).

Principle 9: Mandates can work to make change.

As mentioned in Principle 4, fidelity perspective focuses on the fair use of changes and innovations based on the intentions primary producers have. Such administration needs some mandates approved by responsible high-level managers.

Principle 10: Systematic view on change is needed (Both internal and external factors greatly influence implementation success).

As mentioned in Principle 8, the existence of several factors at work in the change process causes some kind of complexity in the process and its solution is to have a systematic view on change and these intervening factors are seen as a whole. 
Some internal and external factors are at work in succeeding in the change process. Internal factors can be divided in two groups: a) Organization's physical characteristics including its size, resources, space, technologies, plans and users, each of which can facilitate team work and collaboration; b) people factors include attitudes, perceptions, skills and concepts as well as effective leadership and management (based on Principle 7) and the amount and depth of distributed leadership (based on Principle 8). The organizational culture and its norms are of key internal factors positively affecting the change process.

External factors include multiple policies and related ways for response. The societal features and socio-economic conditions of families are of other main external factors (Hall and Hord, 2015).

Principle 11. Adopting, implementing, and sustaining are different phases of the change process.

Adoption that mentioned in Principle 4 is closely related to this principle. Fullan (1985) stated that many studies have been conducted in the late 1960 and during the 1970s reporting that development, diffusion, dissemination, planning and adaptation rarely resulted in real and practical change. This motivated the researchers in curriculum domain to focus on the studies on implementation. In the phase of sustenance, the amount of sustainability of innovations, corrections and changes and their possible consequences can be considered in the system. The sustenance occurs when the change becomes a usual procedure in decision-making, budgeting and so on.

Principle 12. Focus! Focus! Focus!

In the book "Good to Great", Jim Collins (2001) advises change managers to do one thing and do it well. This is the main goal that is planned to be achieved. This is done by conscious selection of the exact goal (Hall and Hord, 2015).

It is necessary to note that some points should be considered applying these principles:

a. They cover some selective, not all aspect of change;

b. They are helpful to explore some assumptions on change;

c. They are beneficial to making effective change (Hall and Hord, 2015).

\section{Problem Statement}

Educational system of any kind needs to adapt itself to different needs society and individuals have. It needs overall change in all aspects of the system, including goals, content, structure, etc. Iran's educational system is not an exception. The necessity of making change in this system in its higher levels has been emphasized. 20-Year Perspective Document for Iran (1995), Iran's Comprehensive Scientific Map (2000), and Strategic Evolution in Iran's Educational System Document (2011) are of documents aimed at achieving the basic change in the system. For operationalization of these documents, Iran's Primary School Curricula (grades 1-6) were changed during 2011-2015.

As noted above, some principles are dominant in the change process. In addition, Hall and Hord (2015) argue that down to up change results in better change, as the thoughts and ideas of individuals experiencing the existed reality in practice are ideal for complete change. Therefore, teachers are ideal individuals for making change. This study aimed to investigate the primary school teachers' viewpoints on the compatibility between Iran's primary school curriculum changes and the 12 Curriculum Change Principles. The teachers' views were studied according to their educational degrees, and employment length as background variables, too.

\section{Method}

Research Method: This research was an applied survey. The research conducted in two phases: a) Deep literature review for stating the different aspects of research problem and extract the main 12 Curriculum Change Principles; b) Making a researcher-made questionnaire and administering it among primary school teachers.

Population and Sample: The study population included all about 1500 primary school teachers of Education Region 1 located in Khorasan Razavi state, Iran. 305 teachers were selected randomly as the research sample. 92 (30\%), 191 (63\%) and 22 (7\%) teachers had A.D. (Associate's Degree), B.D (Bachelor's Degree) and M.D (Master's Degree) as their educational degrees. 52 teachers had employment length less than 10 years (17\%), 67 between $10-20$ years (23\%) and 186 more than 20 years $(60 \%)$.

Research Instrument: The administrated questionnaire included 48 items (4 items for each component of Curriculum Change Principles). The items were in 5-point Likert-type scale ( $1=$ least compatibility-5= highest compatibility). Each subject selected one option based on him/his view on the amount of compatibility of the item with its related Curriculum Change Principle. The validity of the scale was confirmed by 4 specialists in curriculum design. The amount of their agreement was $97.39 \%$. The internal consistency of the scale was 
acceptable $(\mathrm{a}=.78)$. Table 1 shows the internal consistency of each of 12 components included in the questionnaire.

Table 1. The internal consistency of the components included in the questionnaire

\begin{tabular}{lll}
\hline Component (Curriculum Change Principle) & No. of items & $\propto$ \\
\hline $\mathbf{1}$ & 4 & .66 \\
$\mathbf{2}$ & 4 & .66 \\
$\mathbf{3}$ & 4 & .66 \\
$\mathbf{4}$ & 4 & .56 \\
$\mathbf{5}$ & 4 & .76 \\
$\mathbf{6}$ & 4 & .76 \\
$\mathbf{7}$ & 4 & .88 \\
$\mathbf{8}$ & 4 & .78 \\
$\mathbf{9}$ & 4 & .79 \\
$\mathbf{1 0}$ & 4 & .79 \\
$\mathbf{1 1}$ & 4 & .73 \\
$\mathbf{1 2}$ & 4 & .77 \\
Total & 48 & .78 \\
\hline
\end{tabular}

Data Analysis: The selection of a cut-off point is optional and depends on some conditions (Bazargan, 2001). As the research instrument was a paper-and-pencil self-estimated questionnaire in which it was possible that the subject tended to up points, a point above the average one (50\%) was selected as the cut-off point. Selecting the point of $70 \%$ as the agreed-upon cut-off point, some descriptive and inferential statistic methods were used for data analysis in SPSS 21.

\section{Findings}

For determining the amount of consideration of 12 Change Principles in Iran's Primary School Curriculum, the mean rate of each component was estimated with selecting $70 \%$ as the cut-off point ( $\mathrm{x}=11.3$ as the cut-off mean). Using the one-sample t-test, the means of all components were compared with this cut-off point.

Considering the results of one-sample t-test in Table 2, it can be said that principle 7 (with the mean of 12.71), principle 11 (with the mean of 12.45), principle 5 (the mean of 12.07), principle 12 (the mean of 11.65), principle 1 (with the mean of 11.59) and principle 3 (with the mean of 11.50) had significantly higher means than the cut-off mean, respectively. Principle 4 (with the mean of 10.60) and principle 6 (with the mean of 10.74) had significantly lower means than the cut-off mean, respectively $(p<.05)$.

Table 2. The compatibility states of the primary school curriculum with Curriculum Change Principles

\begin{tabular}{|c|c|c|c|c|c|c|}
\hline Change principle & Mean & SD & Mean Difference & $\mathrm{df}$ & $\mathrm{t}$ & p-value \\
\hline 1 & 11.60 & 2.59 & .39 & 304 & 2.65 & $.008^{* *}$ \\
\hline 2 & 11.19 & 2.84 & -.00 & 304 & -.04 & .968 \\
\hline 3 & 11.50 & 3.50 & .30 & 304 & 1.50 & .134 \\
\hline 4 & 10.60 & 2.82 & -.60 & 304 & -3.70 & $.000^{* *}$ \\
\hline 5 & 12.07 & 3.01 & .87 & 304 & 4.91 & $.000 * *$ \\
\hline 6 & 10.74 & 2.96 & -.45 & 304 & -2.68 & .008 \\
\hline 7 & 12.71 & 3.41 & 1.51 & 304 & 7.73 & $.000^{* *}$ \\
\hline 8 & 11.00 & 3.21 & -.19 & 304 & -1.07 & .286 \\
\hline 9 & 10.97 & 3.04 & -.23 & 304 & -1.31 & 190 \\
\hline 10 & 11.07 & 2.93 & -.13 & 304 & -.78 & .435 \\
\hline 11 & 12.45 & 3.24 & 1.25 & 304 & 6.73 & $.000 * *$ \\
\hline 12 & 11.65 & 3.28 & .45 & 304 & 2.40 & $.017^{* *}$ \\
\hline
\end{tabular}

For better comparison of the states of the compatibility of the primary school curriculum with these 12 change principles, they were ranked as depicted in Table 3. Principle 6 and principle 4 fall in the first and last ranks, 
respectively.

Table 3. Ranks of the Change Principles according to their consideration in Iran's Primary School Curriculum

\begin{tabular}{lll}
\hline Rank & Mean & Curriculum Change Principle \\
\hline 1 & 12.71 & 7 \\
2 & 12.45 & 11 \\
3 & 12.07 & 5 \\
4 & 11.65 & 12 \\
5 & 11.60 & 1 \\
6 & 11.50 & 3 \\
7 & 11.19 & 2 \\
8 & 11.07 & 10 \\
9 & 11.00 & 8 \\
10 & 10.97 & 9 \\
11 & 10.74 & 6 \\
12 & 10.60 & 4 \\
\hline
\end{tabular}

For estimating the possible significant difference in teachers' views on the compatibility of the studied curriculum with the Curriculum Change Principles according to their "educational degree", ANOVA test was done. As Table 4 shows, there were significantly differences in their views on principles 1, 5, 7, 9, 11 ( $p<.05)$.

Table 4. The results of ANOVA for estimating the possible significant difference in teachers' views on the compatibility of Iran's Primary School Curriculum with the Change Principles according to their "educational degree"

\begin{tabular}{lllllllllllll}
\hline Principles & 1 & 2 & 3 & 4 & 5 & 6 & 7 & 8 & 9 & 10 & 11 & 12 \\
\hline $\mathrm{F}$ & 3.117 & .883 & 2.224 & .285 & 4.744 & 2.658 & 8.020 & 2.367 & 4.768 & 3.895 & 5.103 & 3.936 \\
& & & & & & & & & & & & \\
$\mathrm{p}$-value & $.046^{* *}$ & .415 & .110 & .752 & $.009^{* *}$ & .072 & $.000^{* *}$ & .0960 & $.009^{* *}$ & .021 & $.007^{* *}$ & .021 \\
\hline$* * \mathrm{p}<.05$ & & & & & & & & & & & &
\end{tabular}

For accurate estimation of the paired possible differences in teachers' views according to their educational degrees, Tukey's test was used. The results showed that:

Regarding Principle 1, the views of teachers with A.D. were significantly different than those of teachers with B.D $(\mathrm{P}=.038)$.

Regarding Principle 5, the views of teachers with A.D. were significantly different than those of teachers with B.D $(P=.026)$ as well as those of teachers with B.D. were different than those of teachers with M.D. $(\mathrm{P}=.038)$.

Regarding Principle 5, the views of teachers with A.D. were significantly different than those of teachers with M.D. $(\mathrm{P}=.02)$ as well as those of teachers with B.D. were different than those of teachers with M.D. $(\mathrm{P}=.038)$.

Regarding Principle 9, the views of teachers with A.D. were significantly different than those of teachers with B.D $(\mathrm{P}=.26)$ as well as the views of teachers with A.D. were different than those of teachers with M.D. $(\mathrm{P}=.048)$.

Regarding Principle 11, the views of teachers with A.D. were significantly different than those of teachers with B.D $(P=.027)$ and the views of teachers with A.D. were different than those of teachers with M.D. $(P=.022)$.

For accurately estimating the possible significant difference in teachers' views on the compatibility of the studied curriculum with the Curriculum Change Principles according to their "employment length", ANOVA test was done again. As Table 5 shows, there were significantly differences in their views on principle 4 only $(\mathrm{p}<.05)$. 
Table 5. The results of ANOVA for estimating the possible significant difference in teachers' views on the compatibility of Iran's Primary School Curriculum with the Change Principles according to their "employment length"

\begin{tabular}{lllllllllllll}
\hline Principles & 1 & 2 & 3 & 4 & 5 & 6 & 7 & 8 & 9 & 10 & 11 & 12 \\
\hline $\mathrm{F}$ & 2.156 & 1.937 & 2.129 & 3.611 & \multirow{2}{*}{2.737} & 2.882 & .612 & 2.539 & 1.770 & 2.669 & .231 & 2.610 \\
& & & & & & & & & & & & \\
p-value & .118 & .146 & .121 & $.028^{* *}$ & .066 & .058 & .534 & .076 & .172 & .071 & .794 & .075 \\
$* *$ p $<.05$ & & & & & & & & & & & &
\end{tabular}

For the estimation of the paired possible differences in teachers' views according to their employment length, Tukey's test was used. The results showed that, the views of teachers with employments of 10 years or less (less-experienced group) were significantly different than those with 20 years or more (more experienced group) $(\mathrm{p}=.022)$.

\section{Discussion and Conclusion}

The success in making change does not depend on what has been written as a draft, but do depend on the interpretations and implementations for change (Wedell, 2009). Teachers are main role-players in all educational plans, especially in curriculum change. Teachers are in front of curriculum change. In addition, effective change in curriculum needs to consider some so-called Curriculum Change Principles. We conducted this study based on 12 main principles of curriculum change.

In Iran's Primary School Curriculum, some of these principles is more considered. The principles relating to learning as an agent needed for change (principle 1), intervention for making change (principle 5), district and school-based leadership as an essential elements of long-term change success (principle 7), systematic view on change (principle 11), considering the school as the primary organizational unit for change (principle 3) and focus on objectives (principle 12) are highly considered. However, organizational and individual roles in making change (principle 4) and appropriate intervention role in reducing resistance to change (principle 6) are less considered by the subjects. Other principles were considered in relatively moderate level, it can be said that in changes made in Iran's primary school curriculum some factors and principles relating to organizational and individual roles in making change and appropriate intervention role in reducing resistance to change need to be emphasized.

Considering the difference in teachers' views on the compatibility of the studied curriculum with the Curriculum Change Principles according to their educational degrees, it can be said that teachers with low educational level (A.D. owners) have more positive attitudes toward the curriculum change than those with high educational levels (B.D. and M.D. owners). Teachers with A.D. degrees think that most principles have been considered in the primary school curriculum.

Considering the difference in teachers' views on the compatibility of the studied curriculum with the Curriculum Change Principles according to their employment length, it can be said that teachers are agreed on the compatibility of the studied curriculum with all principles, but Principle 4 (organizational adoption and individual implementation of change).

Some suggestions can be proposed as follows:

- Policy-makers and designers' more considering the behavioral patterns, needs and interests of ones involved in the change process, especially teachers;

- Applying appropriate intervention for reducing teachers' resistance to change and encouraging their efforts;

- Updating the teachers' knowledge on curriculum change plans and procedures;

- Purposefully aiming at school and its vital role in changing curricula;

- Systematic view on change process and avoiding hurry to make needed change;

- Considering all stakeholders in change plans, including teachers, students, families, heads, learning resources, etc.;

- Collaborating with all involved agents in facilitating curriculum change.

\section{References}

20-Year Perspective Document for Iran (1995). Iran's Supreme Revolutionary Cultural Council. 
Aitken, P., \& Higgs, M. (2010). Developing Change Leaders: the Principles and Practices of Change Leadership Development. Oxford: Butterworth- Heinemann.

Bazargan, Abbas (2001). Educational Evaluation: Concepts, Patterns and Operational Process. Tehran: SAMT Pub. Co. [in Persian].

Fathi-vajargah, Kurosh. (2009). The Main Principles and Concepts of Curriculum Design. Tehran:Ball Pub. Co. [in Persian].

Fitz, J., Davies, B., \& Evans, J. (2006). Educational Policy and Social Production: Class Inscription and Symbolic Control. London: Routledge.

Fullan, M. (1985). Curriculum implementation". International Encyclopedia of Education. N. Posthelwait and T. Husen (Eds.), 1208-1215.

Fullan, M. (2005). Fundamental Change: International Handbook of Educational Change. Springer Dordrecht, Berlin, Heidelberg.

Hall, G. E., \& Hord, S. M. (2015). Implementing Change: Patterns, Principles and Potholes. United States: Educational Leadership.

Hargreaves, A., \& Evanes, R. (1997). Beyond Educational Reform: Bringing Teachers Back in. Buckingham: Open University Press.

Iran's Comprehensive Scientific Map (2000). Iran's Ministry of Education.

Mehrmohammadi, M. (2011). Curriculum: Views and Perspectives. Mashhad: Behnashr Co. [in Persian].

Norman, E. (2006). Curriculum Change in Secondary Schools 1957 - 2004: an Educational Roundabout. London; New York: Routledge.

Strategic Evolution in Iran's Educational System Document (2011). Iran's Supreme Revolutionary Cultural Council.

Wedell, M. (2009). Planning for Educational Change. YHT Ltd, London.

\section{Copyrights}

Copyright for this article is retained by the author(s), with first publication rights granted to the journal.

This is an open-access article distributed under the terms and conditions of the Creative Commons Attribution license (http://creativecommons.org/licenses/by/4.0/). 